\title{
EVOLUCIÓN, ÉTICA Y RELIGIÓN INTRODUCCIÓN AL PENSAMIENTO DE FRANCISCO J. AYALA
}

\author{
DIEGO BERMEJO \\ Universidad de Deusto, Bilbao
}

\begin{abstract}
RESUMEN: El debate de la teoría de la evolución sigue vivo en torno a cuestiones fronterizas suscitadas desde la ética y desde la religión. Francisco J. Ayala, biólogo darwiniano y científico humanista, propone un equilibrio elegante en las relaciones entre ciencia, ética y religión, contra fundamentalismos cientistas y religiosos, considerando la teoría darwiniana de la selección natural como un regalo para la ciencia y para la teología, y defendiendo la compatibilidad de ambas para una visión más rica de la vida humana. Los tres apartados de este escrito pueden valer como una primera introducción al pensamiento filosófico del profesor Ayala, que piensa desde la ciencia, pero más allá de la ciencia: 1) la revolución darwiniana (la ciencia como cuestión de hecho), 2) la naturaleza humana biológica y cultural (la ética como cuestión de valor) y 3) la complementariedad entre ciencia y religión (la religión como cuestión de sentido).
\end{abstract}

PALABRAS CLAVE: Ayala, teoría de la evolución, darwinismo, biología y cultura, ciencia, ética y religión, diseño inteligente.

\section{Evolution, Ethics, Religion \\ Introduction tu Biological Philosophy of Francisco J. Ayala}

ABSTRACT: The debate on the theory of evolution goes on in the boundaries between science and ethics, and science and religion, Francisco J. Ayala, darwinian biologist and humanist scientist, proposes an elegant balance in the relationship between science, ethics and religion, against all kind of fundamentalisms, either scientist or religious, considering the darwinian theory of the natural selection as a gift to science and religion, and defending the compatibility of both in order to achieve a richer view of human life. This paper aims to serve as a first introduction to the philosophical thinking of Profesor Ayala, who thinks from science, but beyond science: 1 ) the darwinian revolution (science as matter of fact), 2) human nature as biological and cultural fact (ethics as matter of value), and 3) the compatibility between science and religion (religion as matter of meaning).

KEY WORDS: Ayala, theory of evolution, darwinism, biology and culture, science, ethics and religion, inteligent design.

\section{InTRODUCCIÓN}

Francisco J. Ayala: Cientifico darwiniano, humanista y popperiano

"Blosse Tatsachenwissenschaften machen blosse Tatsachenmenschen», escribió el filósofo Husserl en su libro sobre la crisis de las ciencias ${ }^{1}$. Pareciera estar respondiendo a esta admonición husserliana el profesor Ayala cuando

1 Husserl, E., Die Krisis der Europäischen Wissenschaften und die transzendentale Philosophie, Felix Meiner Verlag, Hamburg, 1996, 3. Aufl., S. 4. 
afirma en su libro Darwin y el Diseño Inteligente: «Deseo simplemente decir algo que es obvio, pero a veces queda oscurecido por la arrogancia de algunos científicos. Por exitosa que sea, y por universalmente abarcador que sea su tema, una visión científica del mundo es desesperadamente incompleta. Las cuestiones de valor y de sentido están fuera del ámbito científico»². El New York Times calificó hace años a Francisco J. Ayala de «científico renacentista». Con el apelativo se quería poner de relieve el talante humanista, interdisciplinar y transversal de un hombre apasionado por la ciencia de la vida, pero también por la vida más allá de la ciencia. En él se hace patente la superación del divorcio destacado por Snow entre las dos culturas, científica y humanística, con equilibrio elegante.

Científico darwinista. Francisco J. Ayala - actualmente profesor de biología molecular, evolutiva y ecológica; y de filosofía y lógica de la ciencia en la Universidad de California, Irvine- nació en Madrid y, tras su paso por la universidad de Salamanca, se traslada en 1961 a USA, donde en 1964 se doctora en biología en la universidad de Columbia, desarrollando, junto con su maestro Theodosius Dobzhansky, la Teoría Sintética de la Evolución (neodarwinismo). Tras desarrollar su actividad académica en varias universidades (Rockefeller y California-Davis), se establece en la universidad de Irvine (California), en la que recibe el nombramiento de «University Professor» (máxima distinción académica, excepcionalmente concedida por la universidad de California, que detenta en exclusiva en el campus universitario de Irvine, dado que se otorga solamente a un profesor por campus) y desde donde irradia su reconocida proyección internacional.

Como científico (darwiniano convencido), su labor investigadora se centra en la biología molecular y en la genética evolutiva y poblacional, con aportaciones relevantes en temas como: el reloj molecular de la evolución, el origen de la malaria y otras enfermedades parasitarias (mal de Chagas); origen, evolución, estructura y función del ARN en protozoos parásitos y relevancia de los «introns» (elementos aparentemente superfluos, pero imprescindibles) para la conformación de estructuras biológicas. Ha influido en disciplinas próximas como la biología, la genética, la bioquímica o la paleontología.

Autor prolífico, cuenta en su haber con más de 1000 artículos científicos y más de 40 libros (algunos en colaboración), traducidos a diferentes idiomas, que recorren desde temáticas estrictamente científicas del campo de la biología genética hasta filosofía de la biología, bioética y diálogo ciencia-religión.

En cuanto miembro destacado de la comunidad científica internacional, pertenece a un sinnúmero de academias de ciencias y humanidades en todo el mundo y ha sido nombrado doctor honoris causa por más de veinte

2 Ayala, F. J., Darwin y el Diseño Inteligente. Creacionismo, cristianismo y evolución, Alianza, Madrid, 2007, 193. Las obras de Ayala en las notas a partir de ahora se citarán de forma breve. La referencia completa puede verse en la bibliografía final. 
universidades. Ha recibido numerosos premios y condecoraciones, entre los que destacan el Premio Templeton (2010) y la Medalla Nacional de Ciencia de USA (2001)

Científico humanista. Convencido de que no sin ciencia, pero que no sólo ciencia es lo que necesita el ser humano para el desarrollo pleno de una vida devenida evolutivamente en él cada vez más compleja, su inquietud humanista le ha conducido a pensar las fronteras de la ciencia con la filosofía, la ética y la teología: filosofía de la biología (biología-cultura, libertad-determinismo, cerebro-mente, homínido-humano), bioética (manipulación genética, experimentos con células madre) y relaciones entre ciencia y religión (compatibilidad entre ciencia y religión, debate sobre el affaire creacionismo versus evolucionismo en la enseñanza pública en USA y polémica contra la pseudoteoría del Diseño Inteligente). Su afán divulgador ha cristalizado en publicaciones orientadas a facilitar el acercamiento a la ciencia y, sobre todo, a superar prejuicios fundamentalistas tanto en contra como a favor de la ciencia (léase, debate con creacionistas fundamentalistas y defensores del Diseño Inteligente, pero también debate con cientistas materialistas).

Pero, además, su compromiso con la realidad social y política, desde su condición primera de científico, le ha llevado a realizar exitosos trabajos de campo en la lucha por la erradicación de enfermedades parasitarias (malaria, mal de Chagas), a asesorar a instituciones y organismos oficiales: jurídicos (asesor del Tribunal Supremo de USA, para quien elaboró el informe final en el que se basó la sentencia en contra de la enseñanza del creacionismo en la escuela pública como alternativa al evolucionismo, basada en dos argumentos definitivos: los relatos de la creación no son ciencia y el intento de introducir su obligatoriedad en la enseñanza en tanto ciencia vulnera la laicidad de la enseñanza pública); políticos (asesor del presidente Clinton en materias de ciencia y sociedad, y programas de investigación genética; asesor de diversos gobiernos sobre políticas de implementación de $\mathrm{I}+\mathrm{D}+\mathrm{i}$ ); y religiosos (asesor del Vaticano en asuntos fronterizos entre ciencia y religión, creacionismo y evolucionismo, y temas candentes de bioética: manipulación genética e investigación con células madre). Como hombre de acción exitoso y solidario realiza una labor desinteresada y continuada de mecenazgo económico a favor de la ciencia, la universidad y las artes.

Científico popperiano.La así llamada «crisis de los fundamentos científicos», con el cuestionamiento consiguiente del método inductivo clásico (inductivismo ingenuo), ha obligado a la ciencia reciente a repensar su estatuto, función y sentido. La ciencia, desde el falsacionismo popperiano en adelante - estableciendo, como criterio de demarcación propio de la ciencia el método de la falsación de hipótesis y no la verificación-, ha dejado de ser fundamentalista. A esta tradición cabe adscribir al profesor Ayala, cuya relación personal con Karl Popper contribuyó a que, como científico, adquiririera un compromiso decidido con un concepto de ciencia abierta para una sociedad abierta. La ciencia, 
pues, no solamente no debe pretender la candidatura exclusiva a la verdad enfática de las cosas, sino que pone al descubierto, en un ejercicio de autocontención metodológica, incluso las condiciones de posibilidad, presupuestos y límites de todo tipo que confluyen en su teorización y en su praxis; revelando con ello la condición humana y social de «esa cosa llamada ciencia» ${ }^{3}$ que tiende a olvidar el cientismo.

La ciencia ha dejado de ser la «nueva religión», el método científico un medio alético/soteriológico para alcanzar verdad y salvación, y la comunidad científica una casta sacerdotal administradora de su poder sacral. El resultado ha sido una salutífera cura de adelgazamiento del exceso de hybris prometeica que había engordado la ciencia hasta convertirla en referente único de lo real y de lo racional. Pero lo real y lo racional han devenido paulatina y progresivamente complejos. La simplicidad y la transparencia han dejado de ser atributos definidores de lo real y lo racional; también, por tanto, de lo científico. La ciencia sabe de esta complejidad ad intra y ad extra y sabe, también, que todo intento de simplificación conlleva consecuentemente una reducción. Reducción necesariamente naturalista desde el punto de vista metodológico (la ciencia se aplica a fenómenos exclusivamente naturales, sujetos a falsación, cuestiones de «hecho»), pero no indebidamente materialista desde el punto de vista ontológico (la ciencia no debe afirmar ni negar cuestiones de valor y sentido, ajenas a su ámbito, método y objetivo). Ayala expresa esta convicción, por fidelidad rigurosa al método científico, del modo siguiente: «El naturalismo metodológico afirma los límites del conocimiento científico, no su universalidad» ${ }^{4}$. Consciente de que todo fundamentalismo descansa sobre el mecanismo de la absolutización de la simplificación reductora de lo complejo, la ciencia postpopperiana asume con alivio su condición de ser un mapa, no exclusivo ni excluyente, dentro de la variada y legítima pluralidad cartográfica en que se deja decir e interpretar lo que entendemos por real. El error que debe evitar la ciencia es convertir el criterio de demarcación en criterio de negación de la validez epistemológica de otras formas de experiencia y conocimiento (ciertamente no científicos). De ahí que no dude nuestro científico humanista en reconocer: «La ciencia es una forma de conocimiento, pero no es la única. El conocimiento también deriva de otras fuentes, como el sentido común, la experiencia artística y y religiosa, y la reflexión filosófica» ${ }^{5}$.

\section{Cuestiones disputadas: ciencia, ética y religión}

El modo popperiano, pragmatista y democrático, de entender la ciencia de nuestro laureado investigador queda reiteradamente patente en manifestaciones públicas y escritas - en contra, a veces, de colegas como Dawkins o

3 Chalmers, A., What Is This Thing Called Science?, Queensland University Press and Open University Press, 1976 [Trad. esp. ¿Qué es esa cosa llamada ciencia?, Madrid, 1987].

4 Ayala, F. J., Darwin y el Diseño Inteligente, 178.

5 Ibíd., 192. 
Dennett, cuyo materialismo no comparte-, para dejar constancia, primero y siempre, de la grandeza de la ciencia, pero también de sus límites; y, segundo y por eso, del respeto obligado a otras formas de hacer experiencia de mundo, más allá de la pretensión de exclusividad y totalitarismo epistemológicos del cientismo.

Los tres apartados de este escrito tratan precisamente de estas cuestiones, poniendo en evidencia problemas, retos y relaciones que surgen entre los ámbitos de la evolución, la ética y la religión, y pueden valer como una primera introducción al pensamiento del profesor Ayala, que piensa desde la ciencia, pero más allá de la ciencia: (1) las revolución darwiniana (la ciencia como cuestión de hecho), (2) la naturaleza humana biológica y cultural (la ética como cuestión de valor ) y (3) la compatibilidad entre ciencia y religión (la religión como cuestión de sentido).

\section{Ciencia y eVolución: Cuestión De Hecho}

\section{De la revolución copernicana a la revolución darwiniana}

La importancia decisiva de Darwin para completar la revolución científica moderna es un hecho irrefutable. Primero, porque la concepción evolucionista (no exclusiva de Darwin e incluso anterior a Darwin), completada por la teoría darwinista de la selección natural es un hecho científico, es decir, algo comprobado, contrastado, corroborado y aceptado más allá de toda duda razonable; y no una simple "hipótesis», como quisieran algunos de sus $\operatorname{críticos}^{6}$. Segundo, porque la teoría evolucionista darwiniana supuso la naturalización definitiva del mundo. La «revolución copernicana» (de Copérnico a Newton) aportó una nueva concepción del mundo físico, dejando constancia de que el universo, materia en movimiento, obedece a leyes inmanentes que permiten explicar los fenómenos naturales. La «revolución darwiniana» aportó una nueva visión del mundo orgánico, mostrando que todos los seres vivos evolucionan por selección natural desde especies anteriores, a través de la adaptación funcional al medio. A la materia inorgánica en movimiento de la primera revolución científica se sumaba la materia orgánica en movimiento de la segunda. El complejo mundo de la vida quedaba incluido en el dominio metodológico de la ciencia. La «hipótesis Dios» se revelaba definitivamente como científicamente innecesaria para explicar los procesos naturales y, a su vez, «Dios como hipótesis» dejaba de ser objeto de demostración científica por no pertenecer al orden de lo natural.

Desde entonces, pensar, después de Darwin, obliga a situar las cuestiones científicas, filosóficas y teológicas en un nuevo terreno de juego con reglas diferentes, las del naturalismo evolucionista. Ayala resume del siguiente modo la passim.

6 Cf. Ayala, F. J., Evolución, ética y religión, 55 ss.; Darwin y el Diseño Inteligente, 144 ss.; 
aportación excepcional y revolucionaria de Darwin a la ciencia y a la cultura: «Este es el descubrimiento fundamental de Darwin: que hay un proceso que es creativo aunque no consciente. Y esta es la revolución conceptual que Darwin completó: la idea de que el diseño de los organismos vivos pueden explicarse como resultado de procesos naturales gobernados por leyes naturales. Esto no es sino una visión fundamental que ha cambiado para siempre el modo en que la humanidad se percibe a sí misma y su lugar en el universo» ${ }^{17}$.

\section{La peligrosa idea de Darwin}

Este cambio de visión, propiciado por la idea de la evolución por selección natural, es el regalo envenenado que Darwin ha legado a la posteridad. Así lo entiende Dennett, que representa actualmente a quienes interpretan las ideas darwinistas como el triunfo de la mentalidad materialista sobre la tradición teológica y filosófica idealista y, por tanto, celebra como regalo lo que para la cosmovisión tradicional suponía —entiende él— un ácido corrosivo. La "peligrosa idea de Darwin ${ }^{8}$ consistía en desalojar a Dios definitivamente de la naturaleza, porque la naturaleza toda, no solo la naturaleza inanimada sino ahora también la naturaleza animada, podía explicarse por causas naturales. La evolución, en consecuencia, era el resultado de un proceso natural de selección adaptativa al medio que explicaba las transformaciones funcionales de los organismos a entornos variables, y cuyas variaciones y mutaciones se transmitían por herencia. La ciencia podía explicar la historia de la vida y del ser humano, precisamente porque la naturaleza tiene historia y, por tanto, evolución y mutación. Y esa historia se dejar narrar desde la comprensión de sus mecanismos naturales, sin necesidad de recurrir a causas sobrenaturales. Darwin fue consciente desde el principio del alcance y consecuencias de la formulación del Origen común de las especies, tesis que las ciencias empíricas han ido corroborando con el tiempo. El ser humano formaba parte de la historia común de los seres vivos y era un ser vivo más en el proceso evolutivo de la naturaleza viva. El ser humano dejaba de ser el centro de la naturaleza y pasaba a ser una especie más, dentro de la variedad de formas de vida generadas por la misma y por similares procedimientos. Los cimientos de una cosmovisión creacionista, sobrenaturalista y espiritualista parecían tambalearse. Dios no era necesario en el orden explicativo de las causas naturales. Las leyes físicas bastaban para dar cuenta del universo físico; las leyes biológicas, para explicar el universo vivo, incluido el ser humano. El ser humano no pertenecería ya a un orden distinto de ser, debido a una supuesta extranaturaleza o supranaturaleza racional y espiritual, fundamento de su unicidad ontológica, sino a la misma naturaleza común que lo emparentaba con lo animado y, en último término, con lo inanimado. Las diferencias anatómicas y conductuales del animal humano no serían ya esenciales,

7 Ayala, F. J., Darwin's Gift to Science and Religion, 202.

8 Cf. Dennetr, D., Darwin's Dangerous Idea, Simon and Schuster, New York 1996. 
sino graduales; y su singularidad, no más maravillosa ni menos azarosa que la de otros seres vivos dotados de peculiaridades únicas de las que ni siquiera él disponía. Donde Darwin veía "grandeza», no es extraño que otros vieran amenaza. La teología, la filosofía y la ética teocéntricas y/o antropocéntricas que dotaban de razones consistentes al imaginario tradicional, y también moderno, de la centralidad y superioridad del ser humano en el mundo, se veían obligadas a revisar a fondo los presupuestos racionales, por antinaturales, dualistas y espiritualistas, en que descansaban. El desplazamiento antropocéntrico seguía al desplazamiento geocéntrico y parecía confirmar definitivamente el desplazamiento teocéntrico. Se producía una vuelta a la naturaleza, a un cosmobiocentrismo sin Dios, sin Hombre y sin Razón. Porque la naturaleza no conocía otra cosa que diseño adaptativo, no finalidad predeterminada, una mezcla de azar aleatorio y necesidad funcional; diseño sin Diseñador. Porque en la naturaleza no había señal ninguna de intencionalidad, sentido o propósito antrópico o divino. Porque la naturaleza era ciega, indiferente y desconsiderada para con el ser humano. Porque la naturaleza se movía y se transformaba ajena al bien y al mal. Porque la naturaleza en evolución, imperfecta, chapucera e inhóspita, parecía contradecir la idea de un Dios creador, supuestamente omnipotente, omnisciente y omnibenevolente; e invitaba a recharzarlo — caso de existircomo incompetente y sádico.

\section{El regalo de Darwin a la ciencia, a la filosofía y a la religión}

Y, sin embargo, esta conmoción cosmovisional no ha impedido que la visión evolucionista se haya ido imponiendo, a pesar de rechazos teológicos y filosóficos varios. La evolución se acepta como un hecho científico vinculante, como un modo de pensamiento y como una cosmovisión general. La prueba es que no se discute su núcleo fundamental, la naturalización de la vida y del ser humano en un proceso continuo de transformación y variación científicamente explicable, sino la interpretación del hecho y del proceso. No está en discusión que la naturaleza tiene historia, sino el sentido de esa historia, y si es tal y como se narra. Tampoco si la evolución es el resultado de un proceso variable y aleatorio, sino si la evolución es, además, progreso en alguna dirección. No si la naturaleza en cuanto tal carece de sentido, sino si la naturaleza, en cuanto humana, debería tenerlo. No si la evolución se puede explicar sin Dios, sino si Dios, en caso de existir, aportaría algo nuevo a la evolución. No si el relato de la evolución es un relato sugerente, elegante y científicamente consistente, sino si es el único relato posible. No si es incluyente, sino si es excluyente. No, si es ciencia; sino si, además, es ideología. A. Moore escribía en 1890, tras la convulsión provocada por las tesis darwinianas, que, «bajo la apariencia de un enemigo, Darwin había hecho el trabajo de un amigo»" De modo similar pien-

9 Cita original de A. Moore: «...Under the guise of a foe Darwin had done the work of a friend». 
sa S. J. Gould, cuando invita a la lucidez liberadora que produce sumergirse en el «baño de agua fría de la teoría de la naturaleza de Darwin» ${ }^{10}$ ( «the cold bath theory of nature»), para abrirse a la aceptación de la contingencia radical y exponerse a sus consecuencias (no necesariamente ateas, como veremos más adelante). Y F. J. Ayala, darwiniano convencido, ha reiterado la misma idea, convencido de que la aportación de Darwin supone un reto, pero también una oportunidad para pensar de otro modo, y mejor, el mundo, el hombre y a Dios. «El regalo de Darwin a la ciencia y a la religión» ${ }^{3}$ consistiría en devolver a la ciencia lo que es de la ciencia — cuestiones de hecho-, y a Dios lo que es de Dios — cuestiones de sentido.

\section{Selección Natural}

Ayala insiste en varios de sus escritos en poner de relieve que lo específico de la teoría darwiniana de la evolución es la teoría de la selección natural, que el propio Darwin consideraba como "mi teoría» ${ }^{11}$ y su verdadera aportación científica a la concepción evolucionista de la vida que no era exclusivamente suya, como sabemos por la historia de la ideas. La selección natural sería el mecanismo o procedimiento adaptativo que permitiría explicar la unidad de origen (origen o ascendencia común de todos los seres vivos) y la diversidad evolutiva de la vida (variedad de especies). No es, por tanto, una teoría sobre el origen de la vida, sino sobre el diseño de los organismos y la historia de la vida, compartida comúnmente por todos los seres vivos y explicada desde ascendencientes comunes por medio de los factores que dan cuenta de los procesos de su variación. Ese mecanismo no es otro que la selección natural. Y significa, estrictamente hablando, que si la vida es un proceso continuo de descendencia con mutación, entonces el mecanismo que lo explica es el esfuerzo adaptativo de los seres vivos por sobrevivir en medios cambiantes, conservar los cambios exitosos para la supervivencia y transmitirlos a la generación siguiente. La teoría sintética de la evolución — que Ayala representa, continuando las aportaciones de su maestro Dobzhansky, entre otros- completa y perfecciona la teoría de la selección natural, añadiendo a la explicación darwiniana de la adaptación funcional de los organismos al medio como causa de la diversidad mutacional

10 «Instead, Darwin argues, we must simply admit that nature offers no moral instruction at all. We must, in other words, take the ultimate cold bath of immersing ourselves in nature and recognizing that, for this particular quest, we have come to the wrong place. Such a «cold bath» may shock us at first. But as we experience the invigoration of such a bracing surround, we should come to view the immersion as neither grim nor depressing, but exhilarating and liberating. (If we then stop searching for moral truth in material reality, we may finally appreciate nature's fascination and her extensive powers to resolve different, but equally important questions within her own realm. And when we reject the siren song of false sources, we become free to seek solutions to questions of morals and meanings in the proper place —within ourselves. S. J. Gould, Rock of Ages, Vintage, London, 2002 [1999], 196-197.

11 Darwin lo expresa al comienzo de sus Notebooks de 1837-1839; vide F. J. Ayala, Evolución, ética y religión, 45. 
de las especies, la aportación mendeliana de la transmisión genética como mecanismo de la herencia que explica la conservación de los cambios adaptativos, que Darwin no contempló.

Si la actual teoría darwinista de la evolución se puede sintetizar en lo anteriormente expuesto, conviene precisar su alcance filosófico y teológico, para evitar convertirla en una teoría del todo (everything theory) con pretensiones cosmovisionales definitivas y omniabarcantes. Por eso, Ayala se ha esforzado en subrayar, tanto en sus publicaciones de divulgación como en informes oficiales elaborados para la Academia de las Ciencias de EEUU en el contexto de la controversia entre creacionismo y evolucionismo ${ }^{12}$, el carácter científico - y solo científico - tanto del hecho evolutivo de la vida como del mecanismo selectivo/adaptativo/mutacional/genético que lo explica. Lo cual obliga a evitar confusiones y corregir errores, cometidos tanto desde el fundamentalismo religioso como del cientificismo fundamentalista, que coinciden en otorgar a la teoría de la evolución pretensiones extracientíficas. Así, pues, urge corregir algunas ideas erróneas, atribuidas frecuentemente a la teoría de la evolución:

- La evolución no es una teoría sobre el Origen de la vida. Aunque compete a la ciencia indagar sobre los orígenes causales de la historia común de la vida y su variedad, la cuestión filosófico-teológica del Origen no constituye el centro de la teoría de la evolución. El meollo lo constituyen la constatación y explicación del hecho de la evolución y sus mecanismos, siempre a partir de algo ya naturalmente existente - algo que logra exitosamente. No pertenece a la ciencia hacer afirmaciones extracientíficas, aunque afirmaciones estrictamente científicas planteen cuestiones serias a cosmovisiones filosóficas y teológicas en contradicción con ellas.

- Evolución no significa necesariamente progreso. Evolución significa cambio, alteración, transformación, mutación, metamorfosis... La idea de progreso se asocia habitualmente con las de ascenso, mejoramiento, superioridad y escalonamiento perfectivos, bajo supuestos ideológicos de linealidad, necesidad y diseño predeterminados - algo que excede a lo que puede afirmar la teoría de la evolución. A la evolución le basta con el criterio de suficiencia adaptativa. Y la «mejor» adaptación es siempre relativa al medio, a la historia y sus transformaciones; es comparativa, parcial y no uniforme. La idea de perfección no pertenece per se a la teoría de la evolución. La idea de «cambio direccional con mejora cualitativa» podría aceptarse como sinómimo de progreso, siempre que

12 El informe didáctico completo, para explicar la evolución y corregir malas interpretaciones de la misma, preparado para Academia Nacional de Ciencias de EEUU, se puede encontrar en la página web de la Universidad de Berkeley: http://www.wvolution.berkeley. edu y publicado en castellano en la página web de la SESBE (Sociedad Española de Biología Evolutiva): http://www.sesbe.org 
se entienda con respecto a algún criterio determinado, no a todos los posibles $^{13}$.

- Evolución no significa pura arbitrariedad o pura casualidad. La casualidad es un factor de la evolución, pero no es totalmente arbitrario. La mutación aleatoria es la fuente fundamental de variabilidad genética; pero la selección natural, el proceso mediante el cual algunas variantes sobreviven y otras no, no es totalmente aleatorio, es funcionalmente adaptativo y "creativo». El individuo más apto sobrevive, se reproduce y transmite los caracteres probados y resistentes. La evolución es una mezcla complementaria de azar y necesidad en el proceso de adaptación funcional de los seres vivos a sus entornos y la selección natural no es arbitraria.

- Evolución no significa proceso consciente, diseñado y con propósito unidireccional, necesariamente planificado. La teoría de la evolución, en cuanto teoría científica, no otorga valor axiológico o sentido teleológico ni al hecho de la familiaridad común de los seres vivos en su diversidad(ancestro común) ni al mecanismo que lo produce (selección natural). Otorgar una racionalidad sustantiva (genealógica y teleológica) al proceso de la evolución no responde a criterios científicos, sino a criterios de valor y sentido ajenos al método y la praxis científicos.

- La evolución, por eso y por sí misma, no otorga dignidad especial ni superioridad evolutiva a una especie sobre otra (ni siquiera al ser humano). Las especies han evolucionado de modo singular y exclusivo, a partir de linajes comunes que se diversifican en el tiempo, adaptándose a entornos físicos y biológicos cambiantes. La imagen del «árbol de la vida», utilizada en biología, induce a confusión, si se interpreta como escala axiológica. Habría que entenderla mejor como simbiosis de seres que coevolucionan juntos en una diversidad multiforme.

- La evolución no es inmoral. No es moral ni inmoral, sino amoral. Y, por tanto, no se pueden extraer consecuencias antropológicas, éticas y políticas de estrategias de supervivencia biológica, presentes en el reino de los seres vivos, sin incurrir en la falacia naturalista (concluir lo que debe ser de lo que es).

- La evolución no es incompatible con la religión. Es una idea equivocada concluir de la teoría de la evolución la incompatibilidad entre evolución y religión. El malentendido se basa en confundir las funciones y competencias tanto de la ciencia como de la religión. Los ámbitos de su competencia son diferentes: la ciencia se ocupa de cuestiones de hecho - se limita a la explicación y comprensión de fenómenos naturales y la predicción de su ocurrencia a partir de hipótesis falsables-, mientras que la religión se ocupa de cuestiones de sentido que no son competencia de la ciencia; aunque interpretaciones literalistas de textos religiosos

13 Cf. Ayala, F. J., ¿De dónde vengo? ¿Quién soy? ¿A dónde voy?, cap. 11. 
en cuestiones que son competencia de la ciencia - por ser cuestiones referidas al funcionamiento de hechos que la ciencia explica suficiente y competentemente- pueden resultar incompatibles con la evolución.

El carácter científico - y sólo científico- de estas aseveraciones queda fuera de toda duda razonable para el darwiniano Ayala: «El origen evolutivo de los organismos es hoy una conclusión científica establecida más allá de toda duda razonable, dotada de la clase de certidumbre que los científicos atribuyen a teorías científicas establecidas en física, astronomía, química y biología molecular. Este grado de certidumbre más allá de la duda razonable es lo que se implica cuando los biólogos dicen que la evolución es un "hecho"; el origen evolutivo de los organismos es algo que aceptan prácticamente todos los biólogos» ${ }^{14}$. Pero, afirmar la evolución como un hecho científico, no convierte a la teoría de la evolución en una teoría del todo o una teoría final sobre todo (everything theory). Tal desmesura no corresponde al estado actual de la cuestión, que Ayala se apresta a poner de relieve al describir tres grandes cuestiones pendientes - auténticos enigmas sobre los que se volcará la investigación en las próximas décadas y que, sin duda, abrirán nuevas perspectivas y nuevos interrogantes como, por otra parte, corresponde a una ciencia que por fidelidad metodológica debe ser falsable: el enigma ontogenético (transformación/tránsito de huevo en adulto), el enigma filogenético (transformación/tránsito de simio en humano) y el enigma neurobiológico (transformación/tránsito del cerebro en mente). «La biología humana se enfrenta en el siglo XXI a tres grandes fronteras de investigación: la descodifica ${ }^{15}$.

Resumiendo, Ayala destaca la importancia de asumir la evolución como hecho científico (y no simple «teoría»), la necesidad de precisar su contenido (contra interpretaciones erróneas y extralimitaciones competenciales) y la conveniencia de ponerla en diálogo complementario con otras sistematizaciones de la experiencia humana de la naturaleza y su sentido (como la ética y la religión).

\section{Ciencia y Ética: CUestión DE VALOR}

\section{De la biología a la ética}

La evolución biológica se completa con la evolución cultural, más eficaz por intencionada y más rápida por tecnológica. Pero ¿en qué relación mutua se encuentran? ¿Es la moral, por ejemplo, en tanto que universal cultural, una consecuencia necesaria de la biología? ¿Son las normas morales imperativos biológicos? ¿Son los genes los últimos agentes responsables de las acciones morales? ¿Se explican los juicios morales, contenido nuclear de la ética, por

14 Ayala, F. J., Evolución, ética y religión, p. 52; passim.

15 Ayala, F. J., ¿De dónde vengo? ¿Quién soy? ¿A dónde voy?, 322 ss. 
estrictos criterios de selección natural? ¿Representa el comportamiento moral la última estrategia evolutiva al servicio exclusivo de la supervivencia y preservación del material genético humano?

La sociobiología — disciplina reciente que pretende describir las bases biológicas de los comportamientos sociales en los organismos vivos y aplicarlas posteriormente al comportamiento humano- induce a pensar que la ética, como cualquier otra realidad cultural, cumple una función evolutiva al servicio de la biología. Ayala cita la afirmación biologicista de Wilson: «El comportamiento humano - como las capacidades más profundas para la respuesta emocional que lo impulsan y lo guían- es la técnica tortuosa por la que el material genético humano ha permanecido y permanecerá intacto. La moralidad no tiene otra función última demostrable» ${ }^{16}$. Incluso el altruismo obedecería a una predisposición similar. Biologización, por tanto, de la ética; la ética sería un derivado natural de la biología y las normas morales cumplirían un cometido funcionalmente biológico. Frente a esta tesis fuerte del radicalismo biologicista — que se deja explicar desde el celo profesional debido a la disciplina propia, pero que se ve matizado inmediatamente por los propios sociobiólogos en cuanto se profundiza en la relación entre ética y ciencia, hasta el punto de reconocerse explícitamente la diferencia entre ambas y admitir la conveniencia de no incurrir en la falacia naturalista como sana praxis metodológica-, Ayala se posiciona claramente en contra; aunque otorga validez al argumento sociobiológico, siempre que se interprete del modo siguiente: «El argumento del sociobiólogo en relación con la ética normativa no es que las normas de moralidad puedan fundarse en la evolución biológica, sino más bien que la evolución nos predispone a aceptar ciertas normas morales, a saber, aquellas que son coherentes con los "objetivos" de la selección natural. Debido a esta predisposición, los códigos morales humanos sancionan los patrones de comportamiento similares a los que se encuentran en el comportamiento social de los animales» ${ }^{17}$.

Resulta evidente, si no se quiere incurrir en aporías o aberraciones morales serias que no estamos dispuestos a aceptar, que lo biológico no es bueno por ser tal, ni consideramos moralmente bueno todo y solo lo que contribuye a la supervivencia y éxito genético de la especie o grupo. La naturaleza es moralmente neutra. La naturaleza no habla moralmente, no dicta normas éticas. Hacer un juicio de valor sobre la misma trasciende el ámbito competencial de la ciencia y no se puede hacer sin incurrir en la falacia naturalista — salto lógico injustificado del ser al deber ser, de la descripción a la prescripción, de la explicación a la justificación. Incumplir este precepto metodológico lleva a aporías insolubles y a consecuencias indeseables, como ponen de manifiesto el darwinismo social, el racismo, el genocidio o la eugenesia. El rechazo de Ayala a esta postura, a la que califica de errónea, es contundente. Existe, afirma nuestro autor, una

16 Wilson, E. O., On Human Nature, Harvard University Press,. Cambridge, MA, 1978, p. 167; cit. en Ayala, F. J., Evolución, ética y religión, 75; passim.

17 Ayala, F. J., ¿De dónde vengo? ¿Quién soy? ¿A dónde voy?, 278. 
discrepancia entre comportamientos biológicamente determinados y normas morales. Dicho de otro modo, la moral no está exclusivamente al servicio de la biología. Las motivaciones y comportamientos morales (por ejemplo, el altruismo) no siempre sirven a ganancia biológica (que un acto humano sea moralmente bueno no depende de si favorece o no procesos evolutivos naturales).

\section{Sentido moral y norma moral}

Ayala justifica su postura, partiendo de la distinción que Darwin parece insinuar entre sentido moral y norma moral en el pasaje siguiente de su libro Descent of Man (1871) ${ }^{18}$ : «Cualquier animal dotado de instintos sociales bien marcados, que incluyan los afectos paternos y filiales, adquiriría inevitablemente sentido moral o conciencia tan pronto como sus capacidades mentales se hubieran desarrollado tanto, o casi tanto, como en el hombre [...]. No quiero sostener que cualquier animal estrictamente social, si sus facultades intelectuales se volvieran tan activas y tan altamente desarrolladas como en el hombre, adquiriría exactamente el mismo sentido moral que en nosotros [...]; podrían tener el sentido del bien y del mal aunque este les pudiera hacer seguir líneas de conducta muy distintas». Ayala considera fundamental la distinción entre sentido moral y normas morales como guías de conducta, y extrae las siguientes conclusiones de la afirmación darwiniana: el sentido moral sería una consecuencia necesaria de la capacidad intelectual, la inteligencia humana es un resultado de la selección natural, el sentido moral sería un resultado promovido por la misma selección natural pero no directamente, sino indirectamente a través del desarrollo intelectual; el sentido moral, finalmente, no determinaría por sí mismo las normas morales que sancionan como buena o mala una conducta. Cree que las controversias históricas postdarwinistas sobre el origen biológico o cultural de la moral podrían solventarse evitando esta confusión. Se puede afirmar al mismo tiempo el origen biológico, natural, de la moral — predisposición natural a hacer juicios morales, es decir, sentido moral- $\mathrm{y}$ el origen cultural de los códigos morales — prescripción o sanción cultural de conductas humanas como moralmente buenas o malas. De igual manera que la predisposición al lenguaje no determina la lengua concreta que se va a hablar. Un cosa es la capacidad ética y otra las normas éticas. Ayala resume su postura en dos tesis: 1. «los seres humanos son seres éticos por su naturaleza biológica; que los humanos evalúan su comportamiento como correcto o incorrecto, moral o inmoral, como consecuencia de sus eminentes capacidades

18 Ayala, F. J., Evolución para David, 145. Cita original en Ayala, F. J., The Big Questions: Evolution, 168: "Any animal whatever, endowed with well-marked social instincts, would inevitably acquire a moral sense or conscience, as soon as its intellectual powers had become as well developed, or nearly as well developed, as in man... I do not wish to maintain that any strictly social animal, if its intellectual faculties were to become as active and as highly developed as in man, would acquire exactly the same moral sense as ours... They might have a sense of right and wrong, though led by it to follow widely different lines of conduct». 
intelectuales, que incluyen la autoconciencia y el pensamiento abstracto. Estas capacidades intelectuales son productos del proceso evolutivo pero son distintivas de los humanos. Así, sostendré que el comportamiento ético no tiene una relación causal con el comportamiento social de los animales, incluyendo el «altruismo» familiar y recíproco». 2. «las normal morales según las cuales evaluamos acciones particulares como moralmente buenas o malas (así como los fundamentos que pueden usarse para justificar dichas normas morales) son productos de la evolución cultural, no de la evolución biológica. Las normas de moralidad pertenecen, a este respecto, a la misma categoría de fenómenos que las instituciones políticas y religiosas, o las artes, las ciencias y la tecnología. Los códigos morales, como esos otros productos de la cultura humana, son coherentes a menudo con las predisposiciones biológicas de la especie humana y de otros animales. Pero esta coherencia entre normas éticas y tendencias biológicas no es necesaria ni universal: no se aplica a todas las normas éticas de una sociedad dada, ni mucho menos a todas las sociedades humanas» ${ }^{19}$.

Sobre la primera tesis: El ser humano, por tanto, sería ético por naturaleza (por tanto, biológicamente determinado), porque su naturaleza biológica evolucionada al modo humano (es decir, en el proceso adaptativo y selectivo de la especie humana, distintivo del homo sapiens, en su historia evolutiva biológicamente exitosa) determina tres condiciones necesarias del comportamiento moral: la capacidad de anticipar las consecuencias de las acciones, la capacidad de emitir juicios de valor y la capacidad de elegir entre acciones alternativas. En resumen, afirma Ayala, «el comportamiento ético es una atributo del carácter biológico de los humanos, y, por tanto, es un producto de la evolución biológica. Pero no encuentro ninguna evidencia de que el comportamiento ético se desarrollase porque es adaptativo en sí mismo ${ }^{20}$, sino más bien porque es el resultado de capacidades intelectuales exclusivamente humanas, que representan un umbral cualitativo diferente acontecido en la especie humana.

Sobre la segunda tesis: El comportamiento ético del animal humano -afirmará Ayala - no ha surgido como resultado directo de una respuesta adaptativa, sino como resultado indirecto de la evolución de una eminente capacidad intelectual que, posibilitando anticipación, evaluación y elección, convierte al acto moral en acto humano, cultural y no sólo biológico. Predisposición no es determinación. Aunque, genealógicamente hablando, el comportamiento moral puede derivarse de la constitución biológica del ser humano; normativamente hablando, sin embargo, deriva de la evolución cultural. Las normas morales suelen ser, aunque no necesariamente, consistentes con la naturaleza biológica humana; pero ni se pueden ni se deben justificar biológicamente, porque de la biología no derivan imperativos éticos ni valoraciones axiológicas. «La naturaleza biológica es moralmente neutra $»^{21}$. El criterio de la selección natural

19 Ayala, F. J., ¿De dónde vengo? ¿Quién soy? ¿A dónde voy?, 261.

20 Ibid., 267.

21 Ibíd., 277; etiam Ayala, F. J., Evolución, ética y religión, 73. 
utilizado como criterio axiológico solo puede valorar la adaptación exitosa, la supervivencia del más apto, el número poblacional de la especie o grupo, etc., pero ninguno de esos indicadores constituye por sí mismo un criterio ético. Además usar la selección natural o el curso de la evolución para determinar la moralidad de las acciones humanas puede conducir a paradojas — respetar a los virus porque han demostrado competencia adaptativa y mutacionaly dejar de sanar a los seres humanos por el «imperativo biológico» de respetarlos, siendo coherentes con criterios estricta y exclusivamente biologicistas: el potencial mutacional, la resistencia selectiva y el éxito poblacional; sin embargo, consideramos moral curar a las personas e inmoral no hacerlo-. «Para poder considerar algunos eventos evolutivos como moralmente correctos o incorrectos, debemos introducir valores humanos; las evaluaciones morales no se pueden alcanzar tan solo en base a que ciertos eventos ocurren por procesos naturales» ${ }^{22}$, afirma Ayala. «La selección natural es un proceso natural que incrementa la frecuencia de ciertos genes y elimina otros, que origina algunos tipos de organismos en lugar de otros; pero no es un proceso moral o inmoral en sí mismo o en su resultado, de la misma manera que la fuerza de gravedad no es una fuerza cargada de moral, ni lo es la electricidad. Para poder considerar algunos eventos evolutivos como moralmente correctos o incorrectos, debemos introducir valores humanos; las evaluaciones morales no se pueden alcanzar tan solo en base a que ciertos eventos ocurren por procesos naturales» ${ }^{23}$. El argumento, pues, de la sociobiología más biologicista que considera las normas éticas como simples correlatos socioculturales de conductas favorecedoras de la transmisión más exitosa de la dotación genética es para Ayala «equivocado y no escapa a la falacia naturalista» ${ }^{24}$. El científico, también el darwinista, será científico si no franquea indebidamente la frontera de la falacia naturalista que advierte de la ilegitimidad metodológica del salto diferencial e inferencial entre el ser y deber ser. «Las cuestiones de valor y sentido están fuera del ámbito científico $»^{25}$ - sentencia Ayala.

\section{Religión y moral «natural»}

Una cuestión especialmente interesante en el diálogo con la religión es la relación entre religión y una supuesta moral «natural». Una moral «natural» sería aquella cuya normatividad derivaría directa y espontáneamente de la «naturaleza», y en especial de la «naturaleza humana». Pero la «naturaleza humana», desde la concepción evolucionista, es naturaleza cultural, no solo biológica. El reduccionismo biologicista — cultura se reduce a biología y las normas morales, legales y religiosas sirven exclusivamente a intereses genéticos- no da cuenta cumplida del desarrollo histórico y variedad de los sistemas morales, políticos y religiosos. La evolución cultural no siempre está al servicio

22 Ayala, F. J., ¿De dónde vengo? ¿Quién soy? ¿A dónde voy?, 278.

23 Ibid., 277-278.

24 Ibid., 283.

25 Ayala, F. J., Darwin y el Diseño Inteligente, 193. 
de la evolución biológica, ni se se supedita a ella. En línea argumental con lo anteriormente expuesto y la diferencia establecida entre comportamiento o sentido moral (producto natural de la evolución biológica) y códigos o normas morales (producto de la evolución cultural), Ayala se plantea la cuestión de la justificación de las normales morales, algunas de las cuales no contribuyen directamente a la eficiencia biológica e incluso están abiertamente en contra, y que pueden derivar de tradiciones religiosas. La religión, desde el punto de vista evolutivo, es un producto cultural transmitido por herencia sociocultural y contribuye a la gestación de normas y códigos morales que pueden pretender estar fundamentados en la naturaleza humana como fuente de moralidad. Y, al afirmar esto, se estaría dando por supuesto que existiría una conexión necesaria entre creencias religiosas y principios morales. Ayala no comparte esta opinión y sostiene que existe más bien una conexión motivacional o psicológica, no lógica ni ontológica. Cuando se pretende justificar racionalmente un determinado código moral "religioso», que se presume acorde con la naturaleza humana; en realidad, si quiere ser racional, se argumenta más bien desde una concepción elaborada desde premisas culturales sobre la naturaleza humana y el mundo, porque la «naturaleza» humana no dicta normas morales. La evolución cultural ha conservado, corregido y favorecido determinadas normas que, en principio, han supuesto algún beneficio —no siempre biológico- para las comunidades humanas. Las religiones han reforzado motivacionalmente muchos de estos códigos, dotándolos de autoridad añadida y simbologías cohesivas y coercitivas. Pero ni la moral ni la religión son más éticas por ser más «naturales», porque la naturaleza es amoral. Tanto la moral como la religión se construyen teniendo en cuenta datos de la biología, pero la justificación del carácter normativo de los códigos morales respectivo, es decir, la razón del porqué del deber ser moral de un comportamiento frente a otro no obedece, ni debe obedecer, en última instancia, a imperativos biológicos. Los juicios morales son juicios culturales, y la cultura no se reduce a biología ${ }^{26}$.

\section{CIENCIA Y RELIGIÓN: CUESTIÓN DE SENTIDO}

\section{Relación entre ciencia y religión}

La cuestión de las relaciones entre ciencia y religión es otra de las cuestiones fronterizas a la que Ayala aplica su reflexión. La coexistencia entre ambas se articula en torno a tres convicciones: compatibilidad entre ciencia y religión, grandeza y límites de la ciencia, y rechazo de la pretensión cientista de exclusividad epistemológica. Ni oposición ni concordancia: complementariedad.

26 Cf. Ayala, F. J., «Where does morality come from? In: The Big Questions, 168-178; ¿De dónde vengo? ¿Quién soy? ¿A dónde voy?, cap. 8; passim. 
«El universo que observamos tiene precisamente las propiedades que deberíamos esperar si, en el fondo, no hay diseño, ni objetivo, ni bien ni mal, nada sino una ciega y despiadada indiferencia ${ }^{27}$, afirma Dawkins desde su condición de científico y ateo. La ciencia no puede ni debe decir nada más ni, por cierto, mejor. Sólo que el tono, sin duda poético, de la sentencia — que recuerda a una similar de Monod en El Azar y la necesidad ${ }^{28}$ - traiciona en las metáforas antropomórficas que utiliza (ceguera, despiedad, indiferencia) un juicio de valor y (sin)sentido (deber y esperar) que desborda la competencia metodológica y los límites de lo científicamente afirmable (el científico no «observa» ni sentido ni sinsentido, ni «debe esperarlo», en los fenómenos que analiza, sino relaciones entre causas y efectos). Pero, precisamente porque resulta difícil e inevitable no plantearse estas cuestiones y porque la ciencia no puede ni debe responderlas, puede replicar Ayala a su colega: «Por exitosa que sea, y por universalmente abarcador que sea su tema, una visión científica del mundo es desesperadamente incompleta... El conocimiento científico tal vez enriquezca las percepciones estética y moral, e ilumine el significado de la vida y del mundo, pero estos asuntos están fuera del dominio de la ciencia» ${ }^{29}$. Wittgenstein podría ser considerado como inspirador de este talante postcientista, reflejado en una sentencia del final del Tractatus recurrentemente citada: «Sentimos que incluso cuando todas las posibles cuestiones científicas han sido respondidas, nuestros problemas vitales no han sido ni siquiera tocados» ${ }^{30}$.

\section{Compatibilidad entre ciencia y religión y naturalismo metodológico}

En esta frontera de la ciencia, y más allá de la ciencia, cabe plantearse para el científico darwiniano la cuestión de la religión ${ }^{31}$. Ayala sostiene la compatibilidad entre ciencia y religión (dos ventanas abiertas sobre la realidad,

27 Cit. en Ayala, F. J., Darwin y el Diseño Inteligente, 179. Cita original: «The universe we observe has precisely the properties we should expect if there is, at bottom, no design, no purpose, no evil and no good, nothing but blind, pitiless indifference», DawkIns, R., River out of Eden, Basic Books, New Yor, 1995, pp. 131-132.

28 "L'ancienne alliance est rompue: l'homme sait enfin qu'il est seul dans l'immensité indifférente de l'Univers d'où il a émergé par hasard. Non plus que son destin, son devoir n'est écrit nulle part. A lui de choisir entre le Royaume et les ténèbres», Monod, J., Le hasard et la nécessité, Ed. du Seuil, Paris, 1970, 224 [«La antigua alianza se ha roto: el hombre sabe al fin que está solo en la inmensidad indiferente del Universo del que ha emergido por azar. Su deber, como su destino, no están escritos en parte alguna. A él corresponde elegir entre el Reino y las tinieblas»].

29 Ayala, F. J., Darwin y el Diseño Inteligente, 193. 194.

30 «Wir fühlen, dass, selbst wenn alle möglichen wissenschaftlichen Fragen beantwortet sind, unsere Lebensprobleme noch gar nicht berührt sind», L. Wittgenstein, Tractatus logicophilosophicus, WA, Band 1, Suhrkamp Verlag, Frankfurt a.M, 9. Aufl, 1993, S. 85. Cursiva original.

31 Ayala, F. J., Darwin's Gift to science and religion, 172ss.; también en Darwin y el Diseño Inteligente, cap. 9. 
ofreciendo visiones distintas ${ }^{32}$ ). Pero se apresta a interponer una única condición: la reserva metodológica que impide la injerencia competencial entre ámbitos distintos de experiencia (la verdad científica no puede ser negada por la creencia religiosa y la creencia religiosa no es asunto de la ciencia). « ¿El darwinismo excluye las creencias religiosas? ¿Es la ciencia fundamentalmente materialista? - se pregunta Ayala-. La respuesta a la primera pregunta es no. La respuesta a la segunda pregunta es: depende... La ciencia es metodológicamente materialista o, mejor dicho, metodológicamente naturalista. Prefiero la segunda expresión — precisa Ayala — porque "materialismo" a menudo se refiere a una concepción metafísica del mundo, una filosofía que afirma que no existe nada más allá del mundo de la materia, que no hay nada más allá de lo que nuestros sentidos pueden experimentar. Por eso he afirmado que la cuestión de si la ciencia es o no inherentemente materialista depende de si nos estamos refiriendo a los métodos y el ámbito de la ciencia, los cuales permanecen dentro del mundo de la naturaleza, o a las implicaciones metafísicas de la filosofía materialista que afirman que nada existe más allá del mundo de la materia. $\mathrm{La}$ ciencia no implica el materialismo metafísico... Los científicos y los filósofos que afirman que la ciencia excluye la validez de cualquier conocimiento fuera de la ciencia cometen un "error categórico", confunden el método y el ámbito de la ciencia con sus implicaciones metafísicas. El naturalismo metodológico afirma los límites del conocimiento científico, no su universalidad. La ciencia trasciende las diferencias culturales, políticas y religiosas, porque no tiene afirmaciones que hacer sobre estos temas (excepto, de nuevo, en la medida en que el conocimiento científico es negado). Que la ciencia no esté constreñida por diferencias culturales o religiosas es una de sus grandes virtudes. La ciencia no supera esas diferencias negándolas o tomando una posición en lugar de otra. Está más allá de las diferencias culturales, políticas y religiosas, porque estas cuestiones no son asunto suyo ${ }^{33}$. La actitud intelectual de Ayala concuerda en este punto con la postura ya clásica de S. J. Gould, conocida como NOMA («non-overlapping magisteria») y devenida "solución» standard ${ }^{34}$ al supuesto conflicto entre ciencia y religión entre científicos contemporáneos abiertos al diálogo con las creencias religiosas: «He avanzado dos afirmaciones primordiales al designar mi concepción de la relación apropiada entre ciencia y religión como NOMA, o no yuxtaposición de magisterios: primera, que estos dos dominios mantienen

32 Cf. Ayala, F. J., «Religion has nothing to do with science - and vice versa», en The Guardian (28.5.2010) [guardian.co.uk].

33 Ayala, F. J., Darwin y el Diseño Inteligente, 178, cf. la misma idea en Ayala, F. J., Evolución, ética y religión, 83-85; F. J. Ayala, "Religion has nothing to do with science - and vice versa», en The Guardian (28.5.2010) [guardian.co.uk]. Cursivas nuestras. También en AyaLA, F. J., ¿De dónde vengo? ¿Quién soy? ¿A dónde voy?; Evolución para David; Darwin's Gift to Sciencie and Religion; Am I a Monkey?; passim.

34 Actitud calificada por los «nuevos ateos» Dawkins, Harris o Hitchens como «liberal moderada» y descalifacada como perniciosa por demasidado tolerante con la religión. Cf. Dawkins, R., The God Delusion, London, 2006; Harris, S., The End of Faith, London 2004; Hitchens, Сн., God is no Great, London, 2007. 
igual validez y status necesario para un vida humana completa; y segunda, que permanecen lógicamente distintos y totalmente separados en estilos de investigación, no importa cuánto y de qué modo tengamos que integrar las visiones de ambos magisterios para construir la visión rica y plena de la vida tradicionalmente designada como sabiduría» ${ }^{35}$. Aunque no resulta fácil mantener sin malentendidos y tensiones esta actitud de doble reconocimiento del valor y estatus de ambos «magisterios» para una visión completa de la vida, por una parte, y la independencia y autonomía respectiva en sus ámbitos competenciales, por otra $^{36}$; sin incurrir en irenismos concordistas o tolerancia indiferentista. Tampoco, por supuesto, en la actitud arrogante y beligerante de la descalificación mutua y del conflicto irreconciable ${ }^{37}$.

Ayala mira más atrás y encuentra esta actitud ya presente en la hermenéutica cristiana de los Padres de la Iglesia y en la tradición escolástica, cuya metodología exegética de los textos bíblicos no incurría en actitud fundamentalista. Esa actitud que cabe exigir tanto a la ciencia como a la teología. De ahí que a la teología no le conviene hacer afirmaciones en el ámbito científico que sobrepasan su competencia propia. "Silete theologi in munere alieno», cabría recordar con el jurista Gentile (XVI). Ayala recuerda que esta actitud de respeto y no intromisión no ha sido ajena a una sólida tradición de la teología cristiana,

35 «I have advanced two primary claims in designating my conception of the proper relationship between science and religion as NOMA, or non-overlapping magisteria: first, that these two domains hold equal worth, and necessary status for any complete human life; and second, that they remain logically distinct and fully separate in styles of inquiry, however much and however tightly we must integrate the insights of both magisteria to build the rich and full view of life traditionally designated as wisdom». Gould, S. J., Rock of Ages, Vintage, London, 2002 [1999], 58-59.

36 Por eso Gould replica al final de su Rock of Ages (1999) contra la interpretación irenista de su propuesta — contra el sincretismo del concordismo, por una parte, y la «corrección política» del indiferentismo, por otra-: «NOMA does cherish the separate status of science and religion — regarding each as a distinctive institution, a rock of all our ages, offering vital contributions to human understanding. But NOMA rejects the two paths to irenicism on either side of its own tough-minded and insistent search for fruitful dialogue - the false and illogical union of syncretism, and the perverse proposal of "political correctness» that peace may best be secured by the "three monkeys» solution of covering eyes, ears, and mouth». Gould, S. J., Rock of Ages, o.c., 221]

37 «I don't see how science and religion could be unified, or even synthesized, under any common scheme of explanation or analysis; but I also do not understand why the two enterprises should experience any conflict. Science tries to document the factual character of the natural world, and to develop theories that coordinate and explain these facts. Religion, on the other hand, operates in the equally important, but utterly different, realm of human purposes, meanings, and values — subjects that the factual domain of science might illuminate, but can never resolve. Similarly, while scientists must operate with ethical principles, some specific to their practice, the validity of these principles can never be inferred from the factual discoveries of science. // I propose that we encapsulate this central principle of respectual noninterference - accompanied by intense dialogue between the two distinct subjects, each covering a central facet of human existence- by enunciating the Principle of NOMA, or NonOverlapping Magisteria». Gould, S. J., Rock of Ages, o. c., 4-5. 
remontándose a la tradición agustiniana y tomista, y acabando por la postura oficial de la iglesia católica representada últimamente por Juan Pablo II y, en general, por todas las iglesias - excepto las fundamentalistas-, en la que se reconoce, por una parte, la legitimidad y autoridad del conocimiento científico -lejos ya de las condenas y anatemas pasados- en asuntos de la naturaleza; y, por otra, la necesidad de un diálogo con los resultados de la ciencia que pueden iluminar asuntos de fe. La tradición escolástica defendía ya la complementariedad entre razón y revelación, reconocidas como dos fuentes de conocimiento; hasta el punto de que en caso de una contradicción entre ambas - por coherencia lógica, contradicción sólo aparente-, habría que atribuirlo a una interpretación errónea de las Escrituras o a un razonamiento equivocado. Para Santo Tomas, por ejemplo, la creación ex nihilo no exigía necesariamente el presupuesto de la absoluta inexistencia material, incompatible con las categorías aristotélicas del hilemofirmo que consideraba prescriptivas en la «ciencia» de la época. La inerrancia no deriva, para esta tradición hermenéutica que se remonta a los Padres de la Iglesia, de que la Biblia sea un libro de ciencia, sino un libro de salvación. "En el asunto de la forma del cielo, los autores sagrados no deseaban enseñar a los hombres hechos que no fueran de interés para su salvación», enseñaba San Agustín sobre la oportuna interpretación del libro del Génesis, opinión que se complementa con otras del mismo tenor - y que gusta de recordar Ayala-: "Si sucede que la autoridad de la Sagrada Escritura es puesta en oposición a un razonamiento claro y cierto, eso significa que la persona que interpreta la Escritura no la entiende correctamente» ${ }^{38}$. En la misma línea de pensamiento el cardenal Baronio (XVI) formula la frase ( «La Biblia fue escrita para mostrarnos cómo llegar al Cielo, no cómo es el cielo») que Galileo haría famosa: «Repetiré aquí lo que he oído a un eclesiástico que se encuentra en un grado muy elevado de la jerarquía, a saber, que la intención del Espíritu Santo es enseñarnos cómo se va al cielo, y no cómo va el cielo» ${ }^{39}$. Galileo, que fundamenta sus opiniones en los santos padres (sobre todo, San Agustín y San Jerónimo, a quienes cita con frecuencia), plantea en las llamadas Cartas Copernicanas (Lettere Copernicane) y en El Ensayador (Il saggiatore) la que podríamos considerar solución moderna standard al posible conflicto entre verdades religiosas y verdades científicas por medio de la tesis de los dos libros: el Libro de la Biblia y el Libro de la Naturaleza, ambos inspirados por Dios, aunque escritos en caracteres y con intenciones diferentes, y, por tanto, compatibles a condición de una correcta interpretación de las Escrituras (no siempre literal, por consiguiente) en orden a la salvación y de las demostraciones científicas (no «dogmáticas», por tanto) en orden al conocimiento de la naturaleza. Dos

38 De Gen. ad litteram, lib. II, cap. IX; Epístola séptima, Ad Marcellinum.

39 Galileo GalleEI, Lettera a madama Cristina di Lorena granduchessa di Toscana, in: Id., Opere Complete V, p. 319 [Edizione Digitale: www. Portale Galileo]:

«io direi quello che intesi da persona ecclesiastica costituita in eminentissimo grado, ciò è l intenzione dello Spirito Santo essere d insegnarci come si vadia al cielo, e non come vadia il cielo». 
verdades no podrían ni deberían ser contradictorias, si son verdades, según Galileo; ergo... También Juan Pablo II (1981) — cuya cita suele traer a colación Ayala en diversos escritos- habría prolongado esta misma postura hasta la actualidad reciente: «La propia Biblia nos habla del origen del universo y sus componentes, no con el propósito de enunciar un tratado científico sino en orden a establecer las relaciones apropiadas del hombre con Dios y con el universo. Las Sagradas Escrituras desean simplemente declarar que el mundo fue creado por Dios, y con el fin de enseñar esta verdad se expresan en términos de la cosmología conocida en los tiempos del escritor sagrado. Cualquiera otra enseñanza sobre el origen y la composición del universo es ajena a las intenciones de la Biblia, la cual no pretende enseñar cómo se formó el firmamento, sino cómo llegar a cielo» ${ }^{40}$. En esta misma tradición se reconoce el profesor Ayala. De ahí su postura militante contra el tipo de creacionismo, basado en una lectura literal de la Biblia y defendido por creyentes fundamentalistas, que trata de hacer concordar ciencia y Biblia, considerando como criterio de verdad científica la autoridad de la Biblia contra la ciencia.

\section{El regalo de Darwin y el «Diseño Inteligente»}

El darwinismo, para nuestro científico, no sólo no debe verse como un enemigo de la religión, sino en realidad como un regalo ${ }^{41}$. En este punto comparte la opinión de A. Moore (1890) de que «bajo la apariencia de un enemigo, Darwin había hecho el trabajo de un amigo»; convencido de que la aportación de Darwin supone un reto, pero también una oportunidad para pensar de otro modo, y mejor, el mundo, el hombre y a Dios. «El regalo de Darwin a la ciencia y a la religión $»^{3}$ consistiría en devolver a la ciencia lo que es de la ciencia cuestiones de hecho-, y a Dios lo que es de Dios — cuestiones de sentido. Visto así, las consecuencias para la teología de la creación son notables.

El mundo natural se puede explicar, según el darwinismo, como resultado de procesos adaptativos que permiten concluir en la comprobación de la existencia de un diseño funcional (pero no exactamente teleológico) que no precisa per se de un diseñador extranatural («diseño sin Diseñador»). La aportación fundamental de Darwin a la teoría de la evolución consiste en haber puesto en evidencia el mecanismo adaptativo de la selección natural. La selección natural se presenta como un proceso selectivo - no aleatorio, pero tampoco prediseñado- que genera combinaciones adaptativas, resultado de varios factores: la mutación genética, los desafíos medioambientales y la historia evolutiva previa. El profesor Ayala subraya y subscribe este aspecto fundamental de la teoría

40 Cit. in: Ayala, F. J., Darwin y el Diseño Inteligente, 175.

${ }^{41}$ Ayala, F. J., Darwin's Gift to Science and Religion, Joseph Henry Press, Washington, 2007. La expresión original es de John Haught, de quien la toma prestada, en el texto «Darwin's Gift to Theology», in: Russell, R. J., Stoeger, W. R. y Ayala, F. J. (eds.), Evolutionary and Molecular Biology: Scientific Perspectives on Divine Action, Vaticano/Berkeley, 1998, 393-418. 
científica evolucionista que provoca serias controversias con los defensores del llamado «Diseño Inteligente» (Intelligent Design) (hipótesis pseudocientífica que sostiene que la "complejidad irreductible»" de determinadas características complejas, presentes en algunos procesos y elementos de los organismos vivos - como el ojo humano, el sistema inmune o el flagelo bacteriano-, que estarían haciendo posible un "ajuste fino», entre organismos y funciones, sumamente improbable por selección evolutiva, obligaría a postular $-\mathrm{y}$ a exigir- un Programador/Diseñador inteligente, según el viejo argumento de la teología natural de Paley que establecía una relación de necesidad entre la existencia de diseño en la naturaleza y la existencia de un Diseñador). Pero la «teoría» del Diseño Inteligente es, para Ayala, mala ciencia y mala teología. Mala ciencia, porque, entre otras razones, es un argumento ex post empíricamente inverificable, no hay modo de definir la idea de diseño perfecto, y complejidad no exige necesariamente intervención extranatural. Mala teología, porque obliga lógicamente a hacer responsable a Dios del mal en el mundo, contra la idea cristiana de un Dios Creador, omnisciente y bueno.

La evolución describe los procesos de la vida como sumamente contingentes y, por tanto, no ontológicamente necesarios ni teleológicamente proyectados aunque tampoco absolutamente arbitrarios, si se consideran desde el criterio de la funcionalidad adaptativa. Por eso afirma: «El relato científico de estos acontecimientos es incompatible con un plan predeterminado, ya sea impreso desde el principio o a través de sucesivas intervenciones por un Diseñador omnisciente y todopoderoso. La evolución biológica difiere de una pintura o un monumento en que no es el resultado de un diseño preconcebido. El diseño de los organismos no es inteligente, sino imperfecto y, a veces, disfuncional» ${ }^{43}$. Darwin ya fue consciente de la dificultad teológica del tema, como queda constancia en una carta dirigida a Gray (1860): «Con respecto a la visión teológica de la cuestión. Esto me resulta siempre difícil. Estoy confundido. No tengo intención de escribir de modo ateo. Pero reconozco que no veo tan sencillamente como hacen otros, y como debería desear hacer, ninguna evidencia de diseño y bondad por todos los lados. Me parece que hay demasiada desgracia en el mundo... Por otra parte, no puedo estar contento de ningún modo al ver este marivolloso universo, y especialmente la naturaleza del hombre, y concluir que todo es el resultado de la fuerza bruta. Me inclino a mirar todo como resultando de leyes de diseño, con los detalles, buenos o malos, dejados al trabajo de lo que podemos llamar casualidad. No es que me satisfaga este concepto. Siento muy hondamente que el tema en su totalidad es demasiado profundo para la inteligencia humana. Un perro podría también especular sobre la mente de

42 Expresión acuñada por Michael J. Behe, Darwin's Black Box: The Biochemical Challenge to Evolution (1991), teórico del Diseño Inteligente. Argumentación de Ayala sobre el DI, cf. Ayala, F. J., ¿De dónde vengo? ¿Quién soy? ¿A dónde voy?, 206 ss.; también en «Evolución, Creación y Religión en el Siglo xxI: recuperar el diálogo, Fundación Areces, Madrid, 2012, 195-213; Evolución, ética y religión, 41-55; Darwin's Gift to Science and Religion, 15 ss.

43 Ayala, F. J., Evolución, ética y religión, 54. 
Newton ${ }^{44}$. De igual modo, no habría por qué suponer que el ser humano o cualquier animal no hubiera sido producido originalmente por leyes naturales que actúan en el ámbito de la contingencia causal y casual: «No veo razones de por qué un hombre, u otro animal, no pueda haber sido producido originariamente por otras leyes ${ }^{45}$. Pero nada de ello permite extraer conclusiones religiosas o enseñanzas morales. Vida y muerte se pueden explicar naturalmente, en cuanto hechos naturales. Si la vida y la muerte tienen, además o también, un sentido o un valor últimos, no corresponde a la ciencia dilucidarlo.

$\mathrm{Ni}$ determinismo naturalista ni determinismo teológico. El talante darwiniano, estrictamente científico, separa las cuestiones de hecho de las cuestiones de valor y sentido, acepta que la naturaleza es lo que es (y no correspondencia necesaria a nuestros legítimos deseos morales o anhelos de sentido, es decir, moralmente neutra, amoral, ni moral ni inmoral) y, por eso, desde su estricta competencia disciplinar no puede extraer conclusiones ni sobre la bondad o maldad de un posible Diseño ni sobre el propósito final de un posible Diseñador. Se queda en la constatación de dos hechos compatibles desde el punto de vista naturalista pero difícilmente reconciliables desde el punto de vista teológico: la maravillosa complejidad del mundo vivo y su turbadora amoralidad. Pero, al mismo tiempo, el deseo insatisfecho de encontrar respuesta al dolor y sufrimiento aparejado a la contingencia radical de la vida (reconciliar belleza y bondad). Esta zozobra existencial se resuelve en el agnosticismo posterior de Darwin que, desde la ciencia, no puede pronunciarse sobre la no existencia de Dios y tampoco sobre su existencia; dejando la cuestión en suspenso -algo que remite al mysterium iniquitatis de la teología cristiana y a la aporética teodicea-. Humildad y prudencia epistemológicas, a la vez que conciencia y experiencia de la complejidad y seriedad del problema/enigma/misterio de la vida. Darwin no niega, en nombre de la evolución, la existencia de Dios o la moralidad o el sentido de la vida porque no se revelen evidente y necesariamente en la naturaleza. No incurre en el error de negar lo que escapa al dominio de la ciencia, que algunos creyentes cometen, cuando, en nombre de Dios, niegan

44 "With respect to the theological view of the question. This is always painful to me. I am bewildered. I had no intention to write atheistically. But I own that I cannot see as plainly as others do, and as I should wish to do, evidence of design and beneficence on all sides of us. There seems to me too much misery in the world... On the other hand, I cannot anyhow be contented to view this wonderful universe, and especially the nature of man, and to conclude that everyting is the result of brute force. I am inclined to look at everything as resulting from design laws, with the details, whether good or bad, left to the working out of what we may call chance. Not that this notion at all satisfies me. I feel most deeply that the whole subject is too profound for the human intellect. A dog might as well speculate on the mind of Newton». También afirmaba no ver razón suficientemente buena para atribuir ni la muerte ni la vida a un diseño previamente establecido por la naturaleza o por la voluntad de Dios «to believe that their first birth or prodution [sc. of neither man nor gnat] should be necessarily designed». Cit. in: Gould, J. S., Rock of Ages, o. c., 35-36

45 «I can see no reason why a man, or other animal, may not have been aboriginally produced by other laws». Cit. in: Ibid., 202. 
la evolución porque pone en cuestión un concepto determinado de Dios. Ayala sigue la estela de Darwin y no comparte el radicalismo materialista de colegas como Dawkins, que considera erróneo. Para Ayala, existe una contradicción implícita en afirmaciones que, en nombre de la ciencia, niegan validez o reconocimiento, o incluso derecho a la existencia, a la moral o a la religión. «Si el compromiso de la ciencia con el naturalismo no le permite derivar valores, significados o propósitos desde el conocimiento científico, tampoco le permite negar su existencia ${ }^{46}$. Y hace suyas, porque lo son, las declaraciones de la National Academy of Science (USA): «La religión y la ciencia responden a preguntas diferentes sobre el mundo. Que el universo tenga un objetivo o lo tenga la existencia humana no son preguntas para la ciencia... En consecuencia, muchas personas, y entre ellas muchos científicos, mantienen fuertes creencias religiosas y al mismo tiempo aceptan el hecho de la evolución $»^{47}$.

Ayala sigue fiel a esta cautela darwiniana y considera la visión de Darwin un regalo purificador para la teología. La razón estriba, entre otras cosas, en que libra a un supuesto Dios Creador de la responsabilidad de una creación errática y de un «diseño incompetente» que haría difícilmente explicable la contingencia, el mal, el dolor, las chapuzas evolutivas y el juego macabro de la supervivencia; mucho menos justificable todavía, si ese Dios es pretendidamente omnipotente y bueno. «La teoría del diseño inteligente tampoco es buena teología, porque conduce a conclusiones acerca de la naturaleza del Diseñador bastante diferentes de la omnisciencia, la omnipotencia, y la benevolencia que Paley había inferido como atributos del Creador y que la teología cristiana predica de Dios. No es sólo que los organismos y sus partes no sean ni mucho menos perfectas, sino también que las deficiencias y las disfunciones son ubicuas, lo que evidencia un diseño más "incompetente" que "inteligente" ${ }^{48}$. Y, más adelante, tras un análisis de diferentes casos de imperfecciones evolutivas, corrobora la misma idea: «Los ejemplos de deficiencias y disfunciones en toda clase de organismos se pueden multiplicar hasta el infinito, reflejando el carácter oportunista, chapucero, de la selección natural, que lleva a cabo un diseño imperfecto más que un diseño inteligente ${ }^{49}$. De igual modo que Ayala ha defendido con ahínco, contra el fundamentalismo biblista, que «una lectura literal del Génesis es mala para la ciencia y mala para la religión», argumenta decididamente contra los defensores del Diseño Inteligente que, a pesar del renovado argumentario sobre el diseño/Diseñador basado en la supuesta complejidad «irreductible» de determinados procesos biológicos, no representa para Ayala sino una nueva versión del creacionismo

46 Ayala, F. J., Big Questions: Evolution, 192: «If science's commitment to naturalism does not allow it to derive values, meanings or purposes from scientific knowledge, it surely does not allow it to deny their existence either».

47 Ayala, F. J., ¿De dónde vengo? ¿Quién soy? ¿A dónde voy?, 223; también en Big Questions: Evolution; Darwin y el Diseño Inteligente; passsim.

48 Ayala, F. J., Darwin y el Diseño Inteligente, 158.

49 Ayala, F. J., Darwin y el Diseño Inteligente, 159; Big Questions: Evolution; ¿De dónde vengo? ¿Quién soy? ¿A dónde voy?; passim. 
fundamentalista que, en el fondo, más que defender a Dios «blasfema» contra El. «Pero es así como ve las cosas un biólogo preocupado de que Dios no sea calumniado con la imputación de un diseño incompetente» ${ }^{50}$. La hipótesis del Diseño Inteligente no es buena ciencia ni buena teología, para nuestro científico. La teoría darwinista explicaría suficientemente las contingencias evolutivas sin necesidad de apelar a un diseñador a quien habría que tachar de incompetente o sádico. «Los defensores del diseño inteligente - aconseja nuestro científicoharían bien en reconocer la revolución de Darwin y aceptar la selección natural como el proceso que explica el diseño de los organismos, así como las disfunciones, las rarezas, las crueldades y el sadismo que se hallan por todas partes en el mundo de los vivos. Atribuir éstos a una actuación específica por parte del Creador equivale a blasfemia ${ }^{51}$. Ayala considera que la teoría darwiniana de la evolución permite una respuesta natural al problema del mal en el mundo y desatasca el problema de la teodicea, que trata de justificar racionalmente la existencia del mal, incluido el mal físico, involucrando a Dios en el proceso argumentativo que termina resultando aporético, al tener que considerar las imperfecciones del mundo como consecuencia del diseño divino. «La teoría de la evolución proporciona la solución al componente restante del problema del mal. Como las inundaciones y las sequías son una consecuencia necesaria de la estructura del mundo físico, los depredadores y los parásitos, las disfunciones y las enfermedades son consecuencia de la evolución de la vida. No son el resultado de un diseño deficiente o malévolo: las características de los organismos no han sido diseñadas por el Creador. La evolución por medio de la selección natural es la solución al último escollo del problema del mal $\aleph^{52}$. De igual manera, lamenta la apropiación indebida que creyentes fundamentalistas hacen del término «creacionismo" para oponerlo a evolucionismo. La idea creacionista, compartida por la mayoría de los creyentes, de que Dios creó el mundo de la nada, ex nihilo, no está para Ayala en contradicción con la afirmación de la evolución de la vida. No es competencia de la ciencia afirmar la creación ex nihilo del mundo por parte de Dios, porque ni Dios ni la nada pueden ser objeto de estudio propio de la ciencia. La ciencia puede pronunciarse sobre tránsitos relacionales o causales entre estados factuales, entre hechos observables, no entre creencias científicamente indemostrables - Dios y la Nada no son objetos de la ciencia. Al creyente le basta la coherencia entre sus creencias y la ciencia de la evolución ${ }^{53}$. Y, a modo de concisa conclusión, resume su postura con contundencia y rotundidad: «...la ciencia, y en particular la teoría de la evolución, es compatible con la fe cristiana, mientras que el diseño inteligente no lo es ${ }^{54}$. Compatibilidad, por tanto, entre ciencia y religión. Antifundamentalismo, igualmente, tanto en la ciencia como en la religión. «La conclusión que quiero proponer — dirá Ayala_... es que los conocimientos

50 Ayala, F. J., Darwin y el Diseño Inteligente, 162.

51 Ibid., p. 162.

52 Ayala, F. J., ¿De dónde vengo? ¿Quién soy? ¿A dónde voy?, 226. Cursivas originales.

53 Cf. ¿De dónde vengo? ¿Quién soy? ¿A dónde voy?, 227.

54 Ibíd., 16. 
científicos y las crencias religiosas no tienen por qué estar en contradicción. Si se los evalúa de forma correcta, no pueden estar en contradicción, porque ciencia y religión se ocupan de campos de conocimiento que no se superponen. Tan solo al hacer afirmaciones que están más allá de sus fronteras legítimas es cuando la ciencia y las creencias religiosas parecen ser antitéticas» ${ }^{55}$.

\section{Conclusión}

Las reflexiones de este artículo ofrecen una panorámica introductoria a cuestiones disputadas en las fronteras de la ciencia, la ética y la religión que abrirá el apetito a otras lecturas de la extensa bibliografía del profesor Francisco J. Ayala, científico humanista, que profesa con igual intensidad una pasión encendida tanto por la ciencia de la vida como por la vida más allá de la ciencia. La vida no se reduce a la ciencia. La ética no se reduce a biología. La ciencia no es enemiga de la religión. La religión no debe ser enemiga de la ciencia. Ciencia y religión pueden coexistir, porque no pueden contradecirse, si respetan las competencias propias del respectivo ámbito de reflexión y el método propio. La teoría darwiniana de la selección natural es un regalo para la ciencia y para la religión. Francisco J. Ayala, pretende pensar con Darwin y después de Darwin, consciente de que el legado darwiniano obliga a situar las cuestiones científicas, filosóficas y teológicas en un nuevo terreno de juego con reglas diferentes, y atreviéndose a pensar en su radicalidad el hecho de la contingencia de la naturaleza y de la naturaleza humana. A la buena ciencia pertenecen el reconocimiento de los propios límites, rigor metodológico y honestidad intelectual. No otra cosa pretende Ayala en su actividad investigadora y docente. Reduccionismo y dogmatismo no pertencen a la buena ciencia. Separar metodológicamente las cuestiones de hecho, valor y sentido sigue siendo una actitud intelectual eficiente y necesaria, por respeto a la propia ciencia y por respeto a la complejidad de la vida humana. Ayala hace gala de este talante, científicamente humilde y humanamente abierto, apasionado por la ciencia de la vida y por la vida más allá de la ciencia: «El conocimiento científico... es satisfactorio y útil. Pero una vez que la ciencia ha dicho su parte, quedan muchos aspectos de la realidad que son de interés: cuestiones de valor, sentido y propósito que por siempre estarán más allá del ámbito de la ciencia» ${ }^{56}$.

\section{Bibliografía de Francisco J. Ayala (selección)}

- Ayala, F. J., ¿De dónde vengo? ¿Quién soy? ¿A dónde voy? Ensayos sobre la naturaleza humana, la ética y la religión, Alianza Editorial, Madrid, 2015.

55 Ibid., 221. Cursiva original.

56 Ayala, F. J., Darwin y el Diseño Inteligente, 195. 
- Cela Conde, C. J. / Ayala, F. J., Evolución humana. El camino hacia nuestra especie, Alianza Editorial, Madrid, 2015.

- Ayala, F. J., Evolución para David, Laetoli, Pamplona, 2014.

- Ayala, F. J., Evolución, ética y religión, Universidad de Deusto, Bilbao, 2013.

- Ayala, F. J., The Big Questions: Evolution, Quercus, London, 2012. [Grandes cuestiones. Evolución, Ariel, Barcelona, 2012].

- Ayala, F. J. et al. (eds.), In the Light of Evolution. 6 volúmenes [Colloquia of the National Academy of Sciences], The National Academies Press, Washington, 20072011.

- Ayala, F. J., Am I a Monkey?, The Johns Hopkins University Press, Baltimore, 2010. [¿Soy un mono?, Ariel, Barcelona, 2011].

- Barahona, A./Ayala, F. J., El siglo de los genes. Patrones de explicación en genética. Alianza Editorial, Madrid, 2009.

- Ayala, F. J., Darwin's Gift to Science and Religion, Joseph Henry Press, Washington, 2007.

- Ayala, F. J., Darwin y el Diseño Inteligente: creacionismo, cristianismo y evolución, Alianza Editorial, Madrid, 2007.

- Ayala, F. J./ Cela Conde, C. J., La piedra que se volvió palabra: las claves evolutivas de la humanidad, Alianza Editorial, Madrid, 2006.

- Ayala, F. J., La evolución de un evolucionista: escritos seleccionados, Servicio de Publicaciones, Universidad de Valencia, 2006.

- Grisolía, S./Puigdomènech, P./Ayala, F. J., Genética, Nuevas Ediciones de Bolsillo, Madrid, 2003.

- Puigdomènech, P.; Grisolía, S.; Ayala, F. J., Genética, Círculo de Lectores, Barcelona, 2002.

- Ruiz, R./Ayala, F. J., De Darwin al DNA y el origen de la humanidad: la evolución y sus polémicas, Fondo de Cultura Económica, México, 2002.

- Cela Conde, C. J./Ayala, F. J., Senderos de la evolución humana, Alianza Editorial, Madrid, 2001.

- Ayala, F. J., Teoría de la evolución, (Ediciones Temas de Hoy) Editorial Planeta, Barcelona, 1999.

- Ruiz, R./Ayala, F. J., El método en las ciencias. Epistemología y darwinismo, Fondo de Cultura Económica, México, 1998.

- Ayala, F. J., La teoría de la evolución: de Darwin a los últimos avances de genética, (Ediciones Temas de Hoy) Editorial Planeta, 1997.

- Ayala, F. J., Origen y evolución del hombre, Alianza Editorial, Madrid, 1995.

- Ayala, F. J., La naturaleza inacabada, Salvat Editores, Barcelona, 1994.

- Ayala, F. J., Teoría de la evolución, (Ediciones Temas de Hoy) Editorial Planeta, 1994.

- Ayala, F. J./Kiger, J. A., Genética moderna, Ediciones Omega, Barcelona, 1984.

- Ayala, F. J./Dobzhansky, T., Estudios sobre la filosofía de la biología, Editorial Ariel, Barcelona, 1983.

- Ayala, F. J./Valentine, J. W., La evolución en acción, Pearson Alhambra, Madrid, 1983.

- Dobzhansky, Th./Ayala, F. J./Stebbins, G. L./Valentine, J. W., Evolución, Ediciones Omega, Barcelona, 1979. 